\title{
Temporal lobe structure as determined by nuclear magnetic resonance in schizophrenia and bipolar affective disorder
}

\author{
E C JOHNSTONE, D G C OWENS, T J CROW, C D FRITH, K ALEXANDROPOLIS, \\ G BYDDER,* N COLTER \\ From the Division of Psychiatry, Clinical Research Centre, Watford Road, Harrow, Middlesex, UK
}

SUMMARY Temporal lobe structure has been assessed by magnetic resonance imaging in groups of patients with schizophrenia $(n=21)$ bipolar affective disorder $(n=20)$ and normal controls $(n=21)$. In the temporal lobe area a significant $(\mathrm{p}<0.05)$ diagnosis by side interaction was present, the area being less on the left than on the right side in patients with schizophrenia in contrast to findings in the two other groups. Lateral ventricular and temporal horn area did not distinguish the groups as a whole. However, there was a significant $(p<0.05)$ relationship between lateral ventricular area and poor outcome, and in an analysis confined to males, patients with schizophrenia $(n=15)$ were found to have significantly $(\mathrm{p}<0.05)$ enlarged temporal horns.

Computed tomography has demonstrated that some patients with schizophrenia have enlargement of the lateral cerebral ventricles. ${ }^{1-3} \mathrm{~A}$ study of post-mortem brains collected at Runwell Hospital (the Runwell I series) in which brains from schizophrenic patients were compared with those from affectively ill patients ${ }^{4}$ confirmed the finding of reduction of brain substance in schizophrenia but found the most striking differences lay in the temporal lobe. The inferior horns of the lateral ventricle were significantly larger and the width of the parahippocampal gyrus significantly less in the schizophrenic patients. In a further study brains of patients with schizophrenia were compared with normal controls (the Runwell II series). From an initial sample of 56 patients and 56 age-matched controls, brains were excluded if they showed evidence of previous surgery, or significant Alzheimer type or vascular change on histological examination, to give a final sample of 19 schizophrenic patients and 23 controls. The increased size of the lateral ventricles in the schizophrenic patients became increasingly prominent posteriorly and was greatest in the inferior

Address for reprint requests: E C Johnstone, Department of Psychiatry, Clinical Research Centre, Watford Road, Harrow, HA1 3UJ, UK

\footnotetext{
*Present address: Department of Magnetic Resonance Imaging, Royal Postgraduate Medical School, DuCane Road, Hammersmith Hospital, London W12 0HS, UK.
}

Received 19 September 1988 and in revised form 19 November 1988. Accepted 28 November 1988 segment (temporal horn) where there was an increase of $80 \%(\mathrm{p}<0.005)$.

There has been an accumulation of evidence supporting an association between schizophrenia and temporal lobe abnormality. In an extensive review of the literature Davison and Bagley ${ }^{6}$ concluded that there was an association between temporal lobe lesions and schizophrenia. Higher rates of schizophrenia have been found in individuals with temporal lobe epilepsy. ${ }^{711}$ A loss of neuropeptides in the temporal lobe has been found in some schizophrenic patients. ${ }^{1213}$

The area of the inferior (temporal) horns of the lateral ventricle is not well visualised with computed tomography and could not be seen on the scans done at Northwick Park. ${ }^{3}$ However, the inferior (temporal) horn of the lateral ventricles may be visualised with magnetic resonance (MRI). The present study used this technique to compare temporal lobe structure in schizophrenic patients with affective psychosis and normal controls.

\section{Method}

(a) Choice of subjects

The intention of the study was to compare temporal lobe structure in (a) patients with schizophrenia, (b) patients with affective psychosis, and (c) normal controls. CT findings suggest that structural abnormalities in schizophrenia may be greater where there is a degree of chronicity. ${ }^{14}$ Schizophrenic patients with a duration of illness of at least 5 years were therefore selected for the study. Computed tomography has 
shown that there is a strong relationship between age and ventricular size and this association may not be linear. ${ }^{3}$ For this reason all the schizophrenic patients in the study were under the age of 50 years. The sample consisted of 15 males and six females in whom a clinical diagnosis of schizophrenia had been made and who on Present State Examination ${ }^{15}$ on at least one occasion during the course of their illness were placed in an $\mathrm{S}^{+}$category (indicating a central schizophrenic condition). The manic depressive group consisted of 12 males and eight females matched as closely as possible for age with the schizophrenic sample. They were all established cases of bipolar affective psychosis. Not all had had the Present State Examination administered during both phases of their illness but all at various times had conformed to DSM III $^{16}$ criteria for both Major Depressive Episode and Manic Episode. The normal control group were volunteers with no history of psychiatric disorder who were matched as closely as possible for age and sex with the schizophrenic sample. They were principally selected from the staff of the department.

\section{(b) Scanning technique and assessment of scans}

Repeated spin-echo sequences (repetition time $544 \mathrm{~ms}$, echo time $44 \mathrm{~ms}$ ) were performed at $1 \mathrm{~cm}$ intervals in the coronal plane using a Picker prototype magnetic resonance imaging system operated at $0 \cdot 15 \mathrm{~T}$. Slice thickness was $8 \mathrm{~mm}$ and matrix size $128 \times 256$. Six to ten slices were obtained in each case in order to include the whole of both temporal lobes.

Bromide pictures were obtained of every cut. These images were assessed in random order and the measurements were made blind to the identities and diagnostic categories of the patients. Measurements were made using the Joyce Loebl Magiscan Image analyser where areas are calculated from boundaries. Contrast was fixed at 20 and brightness at 10 . The areas measured were coronal surface area, right lateral ventricle, left lateral ventricle, right temporal lobe, left temporal lobe, and on every section in which they were present, right temporal horn and left temporal horn. The magnification used for coronal surface area, lateral ventricles and temporal lobes was $\times 3$ and that for temporal horns was $\times 10$. Measurements were made by $\mathrm{KA}$ and $\mathrm{NC}$ who obtained significant inter-rater reliabilities (ranging from $p<0.002$ to $p<0.0001$ ) on each area assessed.

\section{(c) Clinical and psychological assessments}

Mental state assessments were conducted on the same day as the MRI but as some of the patients had unstable mental states it was considered that these were less useful than the assessments of social functioning which were made using those parts of the rating scale described by Cooper ${ }^{17}$ which concern social liability and self care. Items on economic independence and return to work in Cooper's Scale were omitted as it was considered that in the current economic circumstances these do not necessarily relate closely to the patient's ability to function. Patients who showed a minimum (unimpaired) score were classed as having a good outcome and were contrasted with those who showed positive scores on impairment and were classed as having a poor outcome in a similar way to earlier studies from this department. ${ }^{18} 19$ Psychological assessments conducted on the day of the scan consisted of the WAIS, the National Adult Reading Test ${ }^{20}$ an assessment of handedness ${ }^{21}$ and free recall of a 10 word list to test memory.

\section{Results}

Details of the schizophrenic patients, the manic depressive patients and the normal controls are shown in table 1. Satisfactory scans were obtained from all subjects. The section with the largest measured area for the structure of interest was chosen in each case. Mean values for temporal lobes, temporal horns, lateral ventricles and brain area for both patient groups and for controls are shown in figs 1 and 2 and table 2.

Results were calculated using analysis of variance and the co-variates were (1) age and (2) the external structure for the area of interest, that is temporal lobe for temporal horn, hemisphere for temporal lobe etc.

There was a trend towards a significant relationship between diagnosis and temporal lobe size, $F$ $(2,54)=2.73 ; p<0.08$ and there was a significant diagnosis $\times$ laterality interaction, $F(2,53)=3 \cdot 38$; $p<0.05$. The basis for this is illustrated in fig 1 where it may be seen that the temporal lobes of the schizophrenic patients are slightly smaller than those of the other two groups and that while in the schizophrenic patients the left temporal lobes are smaller than the

Table 1 Details of the schizophrenic and manic depressive patients and controls

\begin{tabular}{|c|c|c|c|}
\hline & Age (yr), Mean, SD (Range) & Social outcome (Cooper et al) & $\begin{array}{l}\text { Education } \\
+=\text { University or equivalent } \\
-=\text { No University or equivalent }\end{array}$ \\
\hline Schizophrenic males $N=15$ & $35 \cdot 6, \mathrm{SD}=5 \cdot 7(27-46)$ & $\begin{array}{l}\text { 6-Good } \\
9 \text {-Poor } \\
\text { Mean Score 3·3, SD } 1 \cdot 4\end{array}$ & $\begin{array}{r}5+ \\
10-\end{array}$ \\
\hline Schizophrenic females $N=6$ & $36 \cdot 8, \mathrm{SD}=7 \cdot 1(26-48)$ & $\begin{array}{l}1-\text { Good } 5-\text { Poor } \\
\text { Mean Score 3.5, SD } 1.0\end{array}$ & $6-$ \\
\hline Manic depressive males $\mathbf{N}=12$ & $35 \cdot 2, \mathrm{SD}=8 \cdot 1(25-49)$ & $\begin{array}{l}9-\text { Good } \\
3 \text {-Poor } \\
\text { Mean Score } 2 \cdot 6, \text { SD } 1 \cdot 2\end{array}$ & $\begin{array}{l}3+ \\
9-\end{array}$ \\
\hline Manic-depressive females $N=8$ & $42 \cdot 5, \mathrm{SD}=8 \cdot 2(27-53)$ & $\begin{array}{l}7 \text {-Good } \\
\text { 1-Poor } \\
\text { Mean Score } 2 \cdot 12, \text { SD } 0.35\end{array}$ & $\begin{array}{c}1+ \\
7-\end{array}$ \\
\hline $\begin{array}{l}\text { Control males } N=16 \\
\text { Control females } N=5\end{array}$ & $\begin{array}{l}32 \cdot 9, \mathrm{SD}=5 \cdot 6(26-43) \\
39, \mathrm{SD}=6 \cdot 5(30-48)\end{array}$ & $\begin{array}{l}\text { Not assessed } \\
\text { Not assessed }\end{array}$ & $\begin{array}{r}16+ \\
4+ \\
1-\end{array}$ \\
\hline
\end{tabular}



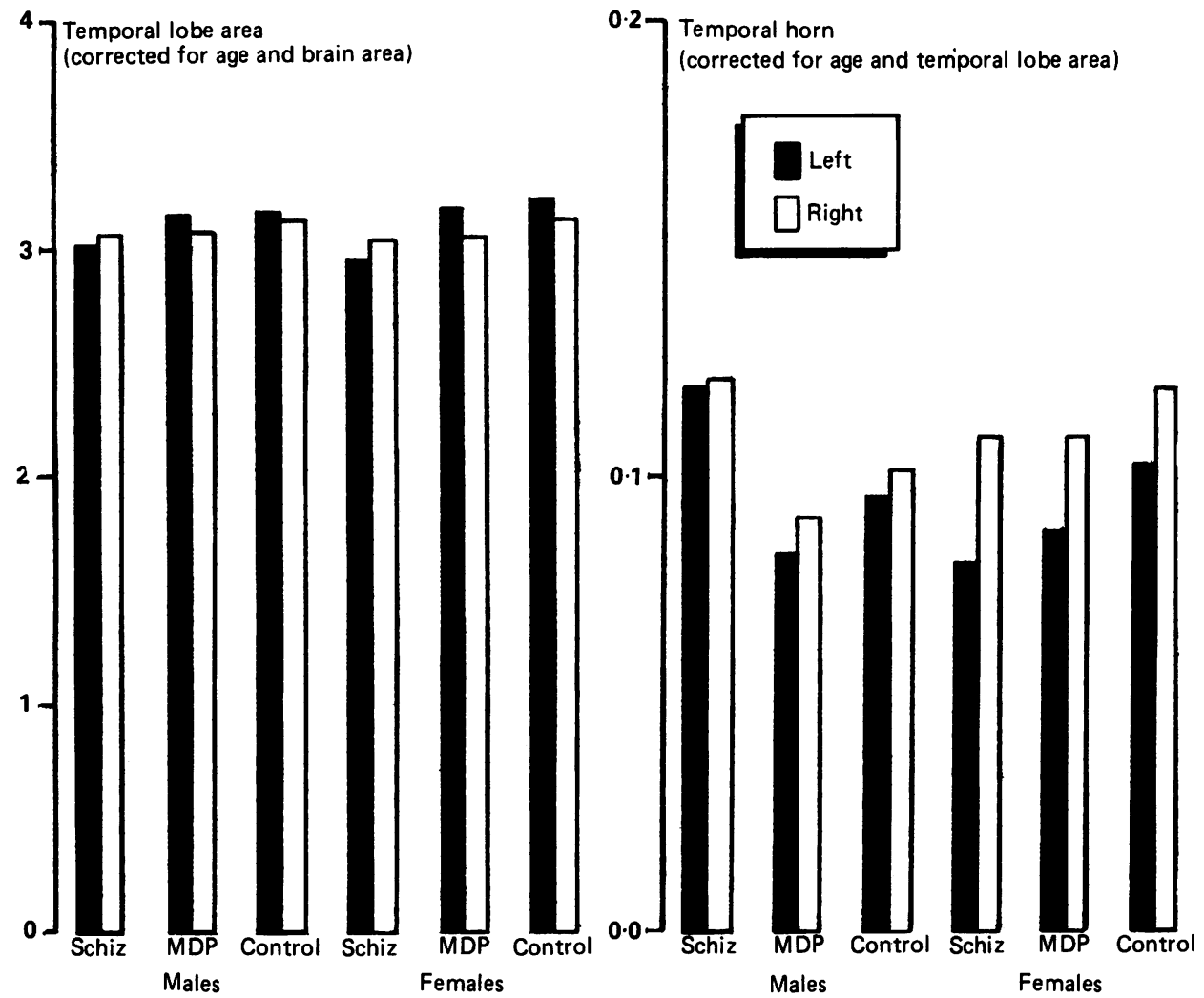

Fig 1 Temporal lobe and temporal horn areas expressed as magiscan units in schizophrenic and manic depressive (MDP) patients and in controls.
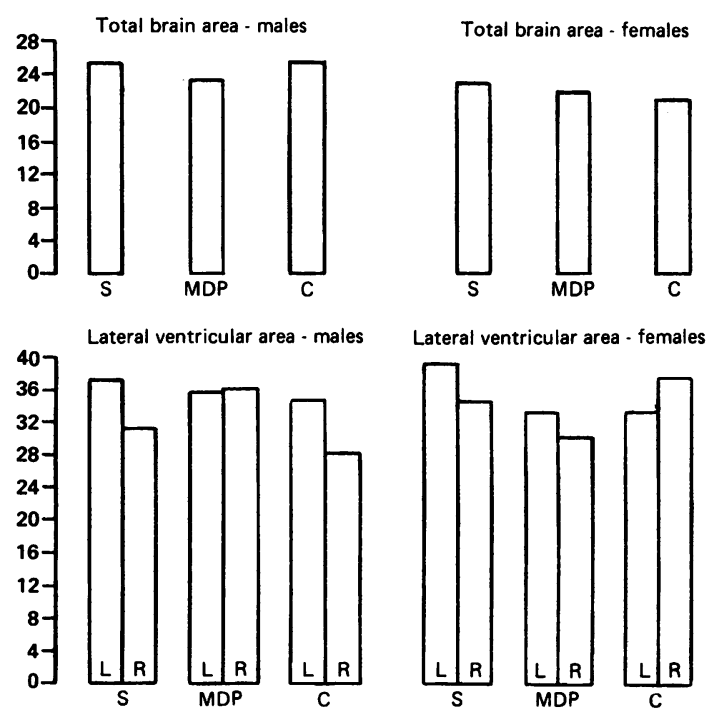

Fig 2 Total brain area and lateral ventricular area expressed as magiscan units in schizophrenic patients $(S)$, manic depressive patients (MDP) and controls $(C)$.

Total brain area - females

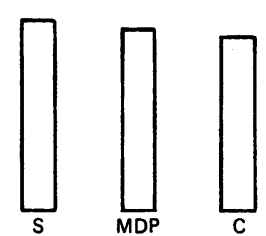
but was unrelated to diagnosis or the other variables considered. Brain area was significantly related to sex (females $<$ males, $\mathrm{p}<0.002$ ). Lateral ventricular size showed a significant positive relationship with age $(\mathrm{p}<0.01)$ and with total brain area $(\mathrm{p}<0.001)$ but no association with diagnosis.

Outcome in terms of the Cooper ${ }^{17}$ scale was significantly poorer in the schizophrenic than the manicdepressive patients $(p<0.01)$ (table 1). Ignoring diagnosis this assessment of outcome was related to the structural measures. There was no significant relationship with temporal horn, temporal lobe, or hemisphere size or with total brain area but there was a significant relationship $(p<0.05)$ between outcome

right, in the manic depressive patients and the controls significant inverse relationship between age and temporal lobe size $(p<0.05)$ and a highly significant positive relationship between temporal lobe size and hemisphere size $(\mathrm{p}<0.00001)$. With this analysis there was no significant relationship between temporal horn size and diagnosis. Hemisphere size showed a 
Table 2 Area measurements of temporal horn, temporal lobe, lateral ventricle and brain (coronal surface) area in the two patient groups and in the controls

\begin{tabular}{|c|c|c|c|c|c|c|c|}
\hline & & \multicolumn{2}{|c|}{ Schizophrenic patients } & \multicolumn{2}{|c|}{ Manic-depressive patients } & \multicolumn{2}{|l|}{ Controls } \\
\hline & & Males $(n=15)$ & Females $(n=6)$ & Males $(n=12)$ & Females $(n=8)$ & Males $(n=16)$ & Females $(n=5)$ \\
\hline Temporal Horn & $\mathbf{L}$ & $0.119(0.052)$ & $0.080(0.031)$ & $0.082(0.031)$ & $0.087(0.49)$ & $0.095(0.046)$ & $0.102(0.022)$ \\
\hline $\begin{array}{l}\text { (Magiscan Units } \times 10 \text { ) } \\
\text { Temporal Lobe } \\
\text { Mean and (SD) }\end{array}$ & $\begin{array}{l}\mathbf{R} \\
\mathbf{L}\end{array}$ & $\begin{array}{l}0.121(0.076) \\
3.01(0.59)\end{array}$ & $\begin{array}{l}0.108(0.044) \\
2.95(0.61)\end{array}$ & $\begin{array}{l}0.089(0.060) \\
3 \cdot 14(0.41)\end{array}$ & $\begin{array}{l}0.108(0 \cdot 085) \\
3 \cdot 17(0 \cdot 34)\end{array}$ & $\begin{array}{l}0.101(0.063) \\
3.17(0 \cdot 49)\end{array}$ & $\begin{array}{l}0.119(0.061) \\
3.22(0.52)\end{array}$ \\
\hline $\begin{array}{l}\text { (Magiscan Units } \times 3 \text { ) } \\
\text { Lateral Ventricle }\end{array}$ & $\begin{array}{l}\mathbf{R} \\
\mathbf{L}\end{array}$ & $\begin{array}{l}3.06(0.50) \\
0.371(0.139)\end{array}$ & $\begin{array}{l}3.04(0.59) \\
0.390(0 \cdot 124)\end{array}$ & $\begin{array}{l}3.06(0.49) \\
0.358(0.171)\end{array}$ & $\begin{array}{l}3.05(0 \cdot 59) \\
0.330(0 \cdot 130)\end{array}$ & $\begin{array}{l}3.12(0.50) \\
0.347(0.096)\end{array}$ & $\begin{array}{l}3.12(0.37) \\
0.333(0 \cdot 101)\end{array}$ \\
\hline $\begin{array}{l}\text { Mean and (SD) } \\
\text { Brainscan Units } \times 3 \text { ) } \\
(\text { Magiscan Mean and }(\text { SD } \times 3)\end{array}$ & $\mathbf{R}$ & $\begin{array}{l}0.313(0.143) \\
28 \cdot 3(3.4)\end{array}$ & $\begin{array}{l}0 \cdot 345(0 \cdot 100) \\
23 \cdot 1(3 \cdot 9)\end{array}$ & $\begin{array}{l}0.360(0 \cdot 146) \\
23 \cdot 4(2 \cdot 5)\end{array}$ & $\begin{array}{l}0.297(0 \cdot 126) \\
21 \cdot 7(2 \cdot 5)\end{array}$ & $\begin{array}{l}0 \cdot 282(0 \cdot 120) \\
25 \cdot 5(2 \cdot 5)\end{array}$ & $\begin{array}{l}0.375(0.078) \\
20.9(1 \cdot 3)\end{array}$ \\
\hline
\end{tabular}

and lateral ventricular size (good outcome mean $=0.307$, SD 0.22; poor outcome $=0.397$, SD 0.39 , that is, a $30 \%$ increase in lateral ventricular size in those with poor as compared with good outcome). There were no significant associations between any structural brain measure and any of the cognitive tests used. When the relationship between cognition and outcome in terms of Cooper ${ }^{17}$ scale was assessed no difference between the good and poor outcome cases was found in premorbid IQ estimate but there was a trend $(p<0.07)$ for those with poor outcome to show poorer current function (in terms of the non-verbal parts of the WAIS). While the analysis of variance of the total sample showed no significant relationship between temporal horn size and diagnosis it appears from fig 1 that while as far as the females are concerned the values for temporal horn size are almost the same in the schizophrenic patients, the manic depressive patients and the controls this is not true of the male subjects. Comparison of temporal horn size shows this to be greater in the male schizophrenic patients $(p=0.05)$ than in other male subjects.

\section{Discussion}

This study has shown differences in temporal lobe structure between schizophrenic patients and comparison groups of manic depressive patients and normal controls. From figs 1 and 2 it is evident that manic depressive patients closely resemble normal controls. The differences between the schizophrenic patients and the others, although significant, are not striking and the difference relating to temporal horn size is confined to male subjects. The differences are less than in our previous post-mortem study. ${ }^{5}$ Without covariation for age or brain size the increase in temporal horn size in schizophrenic patients in this study is $42 \%$ on the left and $26 \%$ on the right. In the earlier post- mortem study 5 the increase was $80 \%$. Possible differences for this lesser difference must be considered. Firstly, it should be noted that the method of assessment is different. In the post-mortem study the area of the temporal horn was assessed radiologically from the lateral aspect; in the present study it is assessed in coronal section. Secondly, there may be differences in the populations of both patients and controls. In the present study the controls were selected from the staff of the department. Our choice of control group was constrained by the limited acceptance of MRI due to the enclosed situation of the subject during the procedure. It was difficult to recruit female subjects to the study which concerned 19 females and 43 males. The control groups did not differ in age from the patients but the female schizophrenic patients differed markedly in educational attainment from the more highly educated female control group. While there were no significant differences between the groups in total brain area the tendency of the female controls to have smaller brain areas and larger right lateral ventricles was not expected; the possibility that this small and atypical control group has been inappropriate must be considered. The fact that schizophrenic/control differences in brain area and lateral ventricular size were not demonstrated is perhaps not surprising in view of the fact that significant differences of this nature have tended to be established in larger samples or in older subjects. ${ }^{14}$ Nonetheless this lack of a general increase in lateral ventricular size in a study in which it was possible, in the male patients, to establish enlargement of the temporal horns of the lateral ventricles, offers some support for the idea that schizophrenic control differences are more prominent in the temporal lobe. ${ }^{5}$

The limited age range of the patient group was selected so that age effects upon the results would be minimised. This does mean that they were many years younger than the patients in the post-mortem study ${ }^{5}$ who had in general died in their 7th and 8th decade. 
Aside from the question of age the samples in the two studies are likely to have differed in severity. The patients in the present study were certainly severely affected by schizophrenia and this is illustrated by their impairments in terms of self care and social liability (table 1) but the patients in the post-mortem study were selected by the fact that they were so severely affected that they could not be discharged, and died in hospital. While some of the schizophrenic patients spend much of their lives as in-patients and it may be anticipated that their illness will run as malignant a course as that of the patients in the postmortem study, this is unlikely to be true of all of them. It should be noted that in the present study the social impairments of the female patients were as severe as those of the male patients (table 1). Although some studies have shown that a poor outcome is less characteristic of schizophrenia in female patients than in male ${ }^{22} 23$ this did not apply to the female patients selected for this study and thus could not be advanced as a possible explanation for the lack of difference in temporal horn size found in the female subjects. The significant association between poor outcome and increased ventricular size suggests that more striking stuctural differences might have been found in a more severely impaired population. For patients of this age group and of this duration of illness, however, the impairments in this sample were severe; some chronic deterioration of function is a feature of each of the patients with schizophrenia in this study. The question of whether the structural brain changes found in some schizophrenic patients represent a progressive process or are due to a developmental defect is an important one which has yet to be resolved..$^{24}$ The difference between the temporal horn enlargement found in this investigation and that in the post-mortem study could be considered as evidence that these changes are progressive.

The laterality aspects of these findings are of some interest. As noted above the temporal horn enlargement on the left is $42 \%$ while that on the right is $26 \%$. The significant diagnosis $\times$ laterality interaction in terms of temporal lobe size reflects the smaller left temporal lobes in the schizophrenic patients. A body of evidence from studies of temporal lobe epilepsy ${ }^{1125-27}$ suggests an association between abnormality of the temporal lobe of the dominant hemisphere and the development of a schizophreniform psychosis. In our post-mortem studies there is evidence for an association between schizophrenia and the left side of the brain. In the Runwell I series ${ }^{4}$ the difference in affective patients was significantly $(p<0.02)$ greater on the left side of the brain; in the Runwell II series ${ }^{5}$ temporal horn enlargement in patients with schizophrenia by comparison with normal controls was significantly greater $(p<0.001)$ on the left side of the brain. No such assymetry was seen in the temporal horn enlargement associated with Alzheimer type dementia. The present finding of an interaction between side and diagnosis in temporal horn area adds to the evidence that cerebral asymmetries are relevant to the disease process in schizophrenia.

In conclusion this study showed significant if modest differences in temporal lobe structure between schizophrenic patients and controls and these related to the left hemisphere. The findings are relevant to the important question of whether or not the structural changes in the brain in schizophrenia are progressive, but they may be interpreted in two ways. On the one hand comparison of the rather modest changes in temporal horn area in the present study with the more striking findings in our post-mortem study ${ }^{5}$ suggests, if the patient populations are comparable, an element of progression. On the other hand, the fact that there are differences in temporal lobe area between schizophrenic patients and the comparison groups suggests that some of this change may be present early, that is that it represents developmental arrest rather than neuronal degeneration.

This study was approved by the Ethical Committee of Harrow Health Authority and was conducted according to its rules. Thanks are due to the patients and the controls for their participation in the study and to Mrs Asmita Soni for typing the manuscript.

\section{References}

1 Johnstone EC, Crow TJ, Frith CD, et al. Cerebral ventricular size and cognitive impairment in chronic schizophrenia. Lancet 1976;it:924-6.

2 Weinberger DR, Wagner RL, Wyatt RJ. Neuropathological studies of schizophrenia a selective review. Schizophr Bull 1983;9:193-212.

3 Owens DGC, Johnstone EC, Crow TJ, et al. Lateral ventricular size in schizophrenia: relationship to the disease process and its clinical manifestations. Psychol Med 1985;15:27-41.

4 Brown R, Colter N, Corsellis JAN, et al. Post-mortem evidence of structural brain changes in schizophrenia: differences in brain weight, temporal horn area and parahippocampal gyrus compared with affective disorder. Arch Gen Psychiatry 1986;43: 36-42.

5 Crow TJ, Colter N, Brown R, et al. Lateralised asymmetry of temporal horn enlargement in schizophrenia. Schizophr Res 1988;1:155-6.

6 Davison K, Bagley CR. Schizophrenia-like psychoses associated with organic disorders of the cerebral nervous system: A review of the literature. In: Herrington RN, ed. Current Problems in Neuropsychiatry. Kent: Headley Brothers, 1969.

7 Hill D. Psychiatric Disorders of Epilepsy. Medical Press, 1953;229:473-5.

8 Pond DA. Psychiatric aspects of epilepsy. J Indian Med Profession, 1957;3:1441-5.

9 Slater E, Beard AW, Glithero E. The schizophrenia-like psychoses of epilepsy. Br J Psychiatry 1963;109:95-150.

10 Ounsted C, Lindsay J. The long-term outcome of temporal lobe 
epilepsy in childhood. In: Reynolds EH, Trimble MR, eds. Epilepsy and Psychiatry. Edinburgh: Churchill-Livingstone 1982;185-215.

11 Trimble MR, Perez MM. The phenomenology of the chronic psychoses of epilepsy. In: Koella WP, Trimble MR. Temporal Lobe Epilepsy, Mania and Schizophrenia and the Limbic System. Basel: Karger, 1982:98-105.

12 Ferrier IN, Roberts GW, Crow TJ, et al. Reduced cholecystokinlike and somatostatin-like immunoreactivity in limbic lobe is associated with negative symptoms in schizophrenia. Life Sci 1983;33:475-82.

13 Roberts GW, Ferrier IN, Lee Y, et al. Peptides, the limbic lobe and schizophrenia. Brain Res 1983;288:199-211.

14 Crow TJ, Johnstone EC. Schizophrenia: Nature of the disease process and its biological correlates. In: Plum F, ed Handbook of Physiology, Bethesda: American Physiological Society.

15 Wing JK, Cooper JE, Sartorius N. The measurement and Classification of Psychiatric Symptoms. Cambridge: Cambridge University Press, 1974.

16 American Psychiatric Association. Diagnostic and Statistical Manual of Mental Disorders, Third Ed. Washington DC, APA 1980.

17 Cooper B. Social class and prognosis in schizophrenia. British Journal of Preventive and Social Medicine, 1961;15:17-41.

18 Johnstone EC, Frith CD, Gold A, et al. The outcome of severe acute schizophrenic illnesses after one year. $\mathrm{Br} J$ Psychiatry
1979;134:28-33.

19 Johnstone EC, Crow TJ, MacMillan JF, et al. A magnetic resonance study of early schizophrenia. $J$ Neurol Neurosurg Psychiatry 1986;49:317-21.

20 Nelson HE, O'Connell A. Dementia: The estimation of premorbid intelligence levels using the new Adult Reading Test. Cortex 1978; 14:234-44.

21 Annett $\mathrm{M}$. The growth of manual preference and speed. $\mathrm{Br} \mathrm{J}$ Psychol 1970;61:545-8.

22 Watt DC, Katz K, Shepherd M. The natural history of schizophrenia a 5 year prospective follow-up of a representative sample of schizophrenics by means of a standardised clinical and social assessment. Psychol Med 1983;13:663-70.

23 Johnstone EC, Owens DGC, Gold A, et al. Schizophrenic patients discharged from hospital-A follow-up study. Br J Psychiatry 1984;145:586-90.

24 Johnstone EC. In vivo and post-mortem evidence of structural changes. In: Helmchen H, Henn FA, eds. Biological Perspectives of Schizophrenia. John Wiley \& Sons. 1987.

25 Flor-Henry P. Psychosis and temporal lobe epilepsy. Epilepsia 1969;10:363-95.

26 Toone BK, Driver MV. Psychosis and epilepsy. Research and Clinical Forums 1980;2:121-7.

27 Lindsay J, Ounsted C, Richards P. Long-term outcome in children with temporal lobe seizures. III Psychiatric Aspects in Childhood and Adult Life. Dev Med Child Neurol 1979;21:630-6. 